\title{
Contribuição à cronologia de Élisée Reclus
}

\author{
Contribution to the chronology of Élisée Reclus
}

\author{
Sergio Aparecido Nabarro \\ Geógrafo, Professor/Pesquisador Visitante na \\ Universidade de Paris (Panthéon-Sorbonne), França \\ sergionabarro@gmail.com
}

\begin{abstract}
Resumo
Élisée Reclus é sem dúvida um dos maiores intelectuais do século XIX. Sua obra, sua compreensão sobre temas como anarquismo e Geografia, vem sendo muito estudada em vários países, incluindo o Brasil. No entanto, a compreensão do aporte teórico-metodológico elaborado pelo pensador ácrata, deve partir também da análise de sua trajetória de vida, marcada pela defesa incessante da liberdade, pela fidelidade às premissas ácratas, pela ação política, por dois longos períodos de exílio e grandes expedições por vários continentes. O propósito deste texto não é analisar as relações entre agência e estrutura, ou a construção do seu método de análise geográfica, mas apresentar ao leitor uma cronologia composta pelos principais fatos ocorridos em sua vida, e que influenciaram sua forma de pensar e interpretar o mundo, visando facilitar a compreensão dos estudos relativos à sua obra. Partimos das cronologias elaboradas por Brun (2014 e 2015) e Ferretti (2016), inserimos novos fatos e detalhes identificados em nossas pesquisas sobre a obra do pensador libertário e cruzamos com apontamentos de estudos menos recentes, como os de Giblin (1971), Lacoste (1981), Andrade (1985) e Vincent (2010).
\end{abstract}

Palavras-chave: Élisée Reclus, Cronologia, Geografia; Anarquismo.

\begin{abstract}
Élisée Reclus is undoubtedly one of the greatest intellectuals of the 19th century. For this reason, his work, his understanding of topics such as anarchism and geography, is widely studied in several countries, including Brazil. However, the understanding of the theoretical-methodological contribution elaborated by the anarchist thinker must also start from the analysis of his life trajectory, marked by the incessant defence of freedom, by the fidelity to the anarchist assumptions, by political action, for two extended periods in exile and great expeditions to many continents. The purpose of this text, however, is not to analyze the relationship between agency and structure, or the construction of its method of geographic analysis, but to present the reader with a chronology composed of the main facts that occurred in his life, which greatly influenced his way of thinking and interpret the world, to facilitate the understanding of studies related to his work. To do so, we started from the chronologies elaborated by Brun (2014 and 2015) and Ferretti (2016), inserted new facts and details identified in our researches about the work of this thinker and relating with notes from traditional studies, such as Giblin (1971), Lacoste (1981), Andrade (1985) and Vincent (2010).
\end{abstract}

Keywords: Élisée Reclus, Chronology, Geography, Anarchism. 


\section{INTRODUÇÃO}

Jacques Élisée Reclus (1830 - 1905) é, sem dúvida, um dos mais importantes geógrafos e intelectuais do século XIX, tanto em relação ao volume ${ }^{1}$ e aprofundamento analítico de sua obra como destacaram Giblin (1971), Lacoste (1981) e Boino (2010) - quanto pela relevância do seu pensamento para a compreensão da sociedade capitalista na transição do século XIX para o XX. Sua concepção de Geografia foi profundamente influenciada por premissas ácratas e pelos contextos social e político europeu do período em que viveu.

Contrariamente ao que já se afirmou em estudos sobre este autor, ainda em vida Reclus obteve um enorme reconhecimento enquanto intelectual, professor e militante. Nas duas últimas décadas do século XIX, por exemplo, suas ideias foram recebidas com enorme prestígio pela comunidade científica de países como França, Bélgica, Brasil e Reino Unido. Entretanto, após sua morte seus aportes sobre geografia, anarquismo, política e sociedade foram "esquecidos" porque suas ideias eram opostas àquelas defendidas pelo projeto político-acadêmico europeu da primeira metade do século XX. Além disso, também não estava em consonância com o entendimento de outros profissionais da área, como Paul Vidal de La Blache, pensador da geografia que gozava de enorme prestígio institucional, considerado o principal nome desta ciência em território francês.

Por muito tempo, ao tentar explicar o abandono das ideias de Reclus, alguns justificavam que os aportes de Paul Vidal de La Blache teriam superado do pensamento de Reclus. No entanto, é preciso lembrar que Élisée Reclus e Vidal de La Blache foram contemporâneos, prova disso é que as principais obras dos dois intelectuais (Tableau de la Géographie de la France - Quadro da Geografia da França, de La Blache, de 1903, e L'Homme et la Terre - O Homem e a Terra, de Reclus, de 1905) foram publicadas em um curto intervalo, como já apontaram Giblin (1971), Besse (2009), Miossec (2009) e Boino (2010). Além disso, o foco espacial, analítico e temático dos autores era muito diferente. Enquanto Reclus destacava relações de poder (opressão do Estado, da Igreja e precarização das relações de trabalho) reproduzidas no bojo de processos como urbanização, avanço das relações capitalistas no campo e educação voltada à manutenção da propriedade privada, La Blache dedicou-se a temas como evolução social e econômica dos lugares. Neste sentido, suas obras coexistiram, portanto, uma não seria a superação da outra.

Atualmente, tanto na França quanto em países como Argentina, Brasil, Colômbia, Espanha, Irlanda, Itália, Rússia e Suíça, vida e obra de Élisée Reclus ainda estão sendo apresentadas

\footnotetext{
${ }^{1}$ De acordo com levantamento realizado por Boino (2010), apenas a obra Nouvelle Géographie Universelle (Nova Geografia Universal), que possui 19 volumes, é composta por 17.873 páginas e 4.290 mapas. Já as obras La terre: description des phénomènes de la vie du globe (A Terra: descrição dos fenômenos da vida do globo) e L'Homme et la Terre (O Homem e a Terra) somam mais de 4.000 páginas. Além delas, Reclus escreveu outros importantes trabalhos, como História de um Riacho e mais de 100 artigos publicados no mundo todo.
} 
ao meio acadêmico, em textos de caráter biográfico sobre o autor (como os de VINCENT, 2010; FERRETI, 2014), ou em traduções de obras originais de Reclus².

No entanto, o entendimento do pensamento de Reclus deve incluir, necessariamente, uma análise da sua trajetória pessoal e militante. Conforme apontou Lacoste (1981), é impossível compreender Reclus isolando aspectos de sua vida de sua obra, ou de sua luta libertária, tendo em vista que ele não foi apenas um geógrafo, nem somente um anarquista, mas um geógrafoanarquista, um intelectual ácrata. Neste sentido, o objetivo deste texto é apresentar e detalhar importantes fatos de sua trajetória a fim de contribuir para a compreensão dos seus aportes geográficos. Não se trata de construir uma biografia ou de analisar a relação entre agência e estrutura, mas de seguir uma sequência cronológica, organizada a partir dos trabalhos de Brun (2014 e 2015) e Ferretti (2016), como condutor da análise.

\section{INFÂNCIA E JUVENTUDE (1830 a 1850)}

Jacques Élisée Reclus nasceu no dia 15 de março de 1830 em Sainte-Foy-la-Grande, uma pequena comuna do sudoeste francês, fundada em 1255 as margens do rio Dordonha, localizada na região de Gironda, aproximadamente 600 km de Paris.

Com poucas relações com a capital do país, a comuna seguia sua pacata dinâmica socioeconômica e religiosa quando nasceu seu habitante mais ilustre, o quarto de quatorze filhos de Zéline Trigant-Marquey e do pastor protestante Jacques Reclus (VINCENT, 2010; BRUN, 2014).

Reclus viveu apenas seu primeiro ano de vida em sua cidade natal, pois, seu pai, o pastor da comuna, se negou a receber recursos públicos para a igreja, e, com isso, ficar condicionado a aceitar passivamente as imposições do poder local sobre o seu trabalho. Diante desta situação, em 1831, a família Reclus se muda para Orthez, uma comuna um pouco maior, localizada no extremo sul da França, região dos Pirineus, próxima à fronteira com a Espanha, onde seu pai passa a exercer seu ministério em uma igreja independente (BRUN, 2015; FERRETTI, 2016), sem estar subordinado às decisões políticas e econômicas do poder local. Nota-se que, desde muito cedo, ainda no seio familiar, Reclus possuía referências comportamentais questionadoras. A situação social/profissional dos pais observadas durante toda a infância bem como as histórias de luta e resistência envolvendo outros membros de sua família extensa (avós ${ }^{3}$, tios e primos), foram importantes para que, anos mais tarde, Reclus começasse a questionar os poderes constituídos, sobretudo, Estado e Igreja.

\footnotetext{
${ }^{2}$ Ver Reclus (2002, 2010 e 2011).

${ }^{3}$ Seu avô, por exemplo, chegou a ser preso por motivos religiosos (FERRETTI, 2010).
} 
Sua infância também foi marcada pelo contato muito próximo com a natureza (bosques, florestas, parques etc.). Passeava por grandes áreas verdes, mas o que sempre lhe chamava atenção eram os rios, elemento da natureza que mais lhe chamou sua atenção durante toda a vida, sobre o qual posteriormente escreveu uma das suas mais importantes obras: Histoire d'un Ruisseau História de um Riacho (RECLUS, 1869).

Mas, além de observador da natureza, o jovem Élisée, a partir dos 10 anos, passou a questionar as ordens do pai, muito rigoroso na visão do filho (VINCENT, 2010). Os questionamentos e os atos de desobediência tornaram-se cada vez mais constantes, por isso, em 1842, pouco antes completar 13 anos, enviado para estudar em uma tradicional instituição protestante, o Colégio dos Irmãos Moraves, localizado na cidade de Neuwied, região norte da Alemanha - onde seu irmão mais velho, Jean-Pierre Michel Reclus, mais conhecido como Élie, já estudava. No entanto, meses depois, Élisée volta a morar com os pais em Orthez por causa dos seus problemas comportamentais na escola, de onde foi expulso. A alegação da instituição de ensino foi de que seus questionamentos constantes desestabilizavam a organização do estabelecimento de ensino muito conhecida por ser rigorosa e inflexível (CUBERO, 2002).

Entre 1842 e 1847, o jovem e ainda mais questionador Élisée Reclus conclui seus estudos básicos em uma escola pública de Orthez. No ano seguinte, por pressão dos pais que insistiam para seguisse a profissão de pastor, Reclus e seu irmão mais velho iniciam seus estudos universitários em teologia na Faculdade de Teologia Protestante de Montauban, cidade localizada no centro-sul da França, próxima a Toulouse.

Neste período, Élisée e Élie moravam em uma área rural e tinham de caminhavam alguns quilômetros até a faculdade, localizada na área urbana. No caminho, nem pensavam em Teologia, mas observam e analisam a paisagem tentando encontrar respostas para explicar sua organização a partir do modo de vida das pessoas que residiam ali (VINCENT, 2010). Além disso, na faculdade, estavam mais interessados na leitura dos livros de filosofia que nas obras religiosas (FERRETTI, 2016).

Longe dos pais, mais livre, o interesse de Reclus pelo estudo da paisagem crescia na mesma medida que sua vontade de participar de ações de movimentos contestadores da organização social e política francesa. Por isso, as constantes ausências nas aulas, para realizar curtas viagens de observação do Mediterrâneo, causou sua expulsão da faculdade (FERRETTI, 2016). No entanto, sustentava que sua expulsão estava relacionada à sua defesa de ideias republicanas porque, neste mesmo período, estava muito bem informado sobre tensões sociais que ocorriam em Paris, noticiadas nos boletins informativos existentes no interior da França. Foi, portanto, entre os anos de 1848 e 1849 que Reclus volta seus interesses também à compreensão da luta de classes na Europa, seus fundamentos e sua relação com as diversas formas de poder. Para tanto, encontrou sustentação 
teórico-analítica nos escritos de Pierre-Joseph Proudhon, filósofo e economista francês do século XIX, considerado um dos mais importantes pensadores do anarquismo e que defendia a coletivização dos meios de produção, o fim da propriedade e de qualquer forma de hierarquia ${ }^{4}$.

\section{COMPREENSÃO DAS CONTRADIÇÕES DO MUNDO (1850 a 1857)}

Mesmo não tendo concluído um curso universitário, a dedicação de Élisée Reclus aos estudos sobre política era muito grande. Em 1850, escreveu seu primeiro texto, intitulado Développement de la Liberté dans le Monde - Desenvolvimento da Liberdade no Mundo no qual, mesmo ainda não se assumindo anarquista, defende a anarquia como forma mais adequada de organização social (RECLUS, 1925). Seu empenho nos estudos chamou atenção até mesmo dos professores da sua antiga escola em Neuwied na Alemanha, para o qual foi convidado a ser professor (ANDRADE, 1985). Porém, em 1851, incomodado com os métodos tradicionais e autoritários da escola, decide deixar a docência e se mudar para Berlim.

Nos primeiros dias na capital matricula-se na Universidade de Berlim em uma série de cursos sobre geografia comparada. Um deles foi ministrado por Karl Ritter, autor de Erdkunde ${ }^{5}$, obra que muitos anos depois serviu como referência para Reclus organizar e escrever a Nova Geografia Universal.

Em abril de 1851, Élisée Reclus, após estudar uma série de obras sobre os princípios do anarquismo $^{6}$, envia uma carta à família informando sua decisão de abandonar o sacerdócio e lutar pelos ideais libertários (VINCENT, 2010; ANDRADE, 1985). Para Cubero (2002, p. 11), neste momento, "Reclus já tinha formado o núcleo central de suas ideias que depois concebeu e defendeu por toda a vida".

Dias após o envio da carta, o anarquista em formação caminhando quase $700 \mathrm{~km}$ por 14 vários dias em território alemão até chegar a Estrasburgo, cidade francesa na fronteira com a Alemanha, onde encontra o com seu irmão Élie e, juntos seguem para Orthez onde reencontra seus pais e oficializa o abandono do ministério pastoral, mas ainda não os informa do seu envolvimento com os ideais anarquistas.

Dezembro de 1851 marca uma enorme mudança na vida de Reclus porque, ainda residindo com os pais em Orthez, os irmãos Élie e Élisée lideraram uma série de manifestações contra as tentativas de golpe de Estado de Luís Bonaparte. No entanto, dias depois das revoltas que tomaram

\footnotetext{
${ }^{4}$ Ver PROUDHON, 1840.

5 Termo em alemão usado para designar Geografia. É importante salientar que Erdkunde não é a tradução literal da palavra Geografia do grego (Geo=Terra e Grafia=descrição/escrita). O sentido de Erdkunde para Ritter estava voltado ao estudo da relação homem-natureza.

${ }^{6}$ Segundo Cubero (2002) e Silva (2016), a adesão pública de Élisée Reclus ao anarquismo só ocorreu na década de 1860, sobretudo após a sua participação na Associação Internacional dos Trabalhadores, conhecida como Primeira Internacional.
} 
boa parte do território francês o golpe seria consumado. Luís Bonaparte se autoproclamou Napoleão III e deu início ao Segundo Império Francês. Os irmãos passaram a ser perseguidos pela guarnição local (FERRETTI, 2016) e, para não serem presos, fogem para Londres.

Após pouco mais de quatro meses passando por muitas dificuldades financeiras e Londres, Reclus aceita uma oferta de emprego como administrador em uma fazenda da Irlanda, país que vivenciava uma grave crise relacionada à dominação e expropriação da população local por capitalistas ingleses.

Os contextos político, econômico e social irlandês foram fundamentais para a construção do pensamento de Reclus. Segundo Andrade (1985, p. 12) “curioso e inquieto, ele viajou pela ilha e procurou compreender as razões que levaram a Irlanda a uma crise econômica sem precedentes e à emigração de sua população para os Estados Unidos". Tentando compreender os problemas sociais causados pela dominação inglesa, bastante latente na Irlanda, em 1852 Reclus elabora um esboço de sua primeira grande obra La Terre (FERRETTI, 2016), só escrita e publicada quinze anos depois.

Após um ano de muito trabalho na fazenda irlandesa, e engajado em compreender o fenômeno migratório dos irlandeses para o continente americano, em 1853 Élisée Reclus decide também emigrar, embarcando para os Estados Unidos da América. Os custos da viagem foram pagos com o trabalho de cozinheiro a bordo.

Os anos de Reclus nos Estados Unidos (1953 a 1955) consolidam definitivamente seu pensamento sobre religião, sociedade e poder, tendo em vista que, ao chegar a Nova Orleans, no extremo do país, trabalhou como preceptor - uma espécie de professor/tutor responsável por ensinar conhecimento gerais a filhos de famílias abastadas - de três filhos de um grande fazendeiro escravista. Diante deste cenário, a profunda indignação com o sistema escravista americano, baseado na grande propriedade monocultora, orienta sua produção intelectual. Além disso, sua aversão ao apoio da igreja aos grandes latifundiários foi o elemento que faltava para sua conversão ao ateísmo.

A partir da compreensão da realidade americana, Reclus insere em seus textos sobre política e sociedade debates sobre temas como a luta contra a escravidão e contra o racismo. Além disso, suas expedições pelo rio Mississippi e pelo lago Michigan lhe serviram para escrever seu primeiro artigo, intitulado Lettres d'un voyageur ${ }^{7}$, publicado no jornal L'Union em Nova Orleans (FERRETTI, 2016).

Mas conhecer apenas um país das Américas não era suficiente para Reclus. Portanto, com o intuito de compreender melhor a realidade e as contradições do continente, em 1855 Reclus parte para Nova Granada (atual Colômbia), passando por vários países da América Central.

\footnotetext{
${ }^{7}$ Primeiro texto no qual Reclus assina e expõe seu nome ao público.
} 
Em terras colombianas, acreditou que a partir da experiência adquirida como administrador de fazenda na Irlanda poderia fundar uma área de colonização sem escravidão. Seu objetivo ao lotear uma grande área em pequenos lotes era atrair cinco mil famílias em apenas cinco anos, formando uma colônia mais humana às margens do rio Hecla, em Serra Nevada de Santa Marta, extremo norte de Nova Granada (ANDRADE, 1985; FERRETTI, 2016). No entanto, dois anos após a fundação da primeira área agrícola, Reclus se convence de que a lógica colonizadora que atraia imigrantes europeus às terras latino-americanas era a capitalista, baseada na grande propriedade privada, na monocultura, na exploração do trabalho alheio, sobretudo, no discurso do rápido enriquecimento, que não mostrava nenhuma preocupação com o meio ambiente.

Frustrado com o fracasso do seu projeto e com a saúde debilitada por ter contraído malária, Reclus abandona seu projeto em terras americanas e retorna à França em 1857. Outro fator determinante para o seu retorno foi a volta do seu irmão Élie, anistiado pelo regime de Napoleão III (FERRETTI, 2014; 2016).

\section{A CARREIRA DE ESCRITOR E SUA MILITÂNCIA (1858 a 1871)}

De volta à França, e estabelecido em Paris, a convite de Luís Hachette - um conhecido editor francês que se dedicava à publicação de materiais didáticos - Reclus passa a trabalhar como escritor sendo o responsável pela redação de guias turísticos em um projeto dirigido por Adolphe Joanne - um jornalista, escritor e tradutor francês especializado em materiais geográficos. Neste mesmo ano Reclus se casa com Clarisse Brian, uma francesa, filha de senegaleses (BRUN, 2014; FERRETTI, 2016).

O desempenho de Reclus como escritor, sobretudo em suas análises dos lugares que conheceu, o fez receber o convite para participar das reuniões da Sociedade Geográfica de Paris ${ }^{8}$ instituição pela qual publica, em 1859, o famoso artigo Étude sur les fleuves - Estudo sobre os Rios, no qual apresenta o conceito de bacia, desenvolvido com maior profundidade na obra Histoire d'un Ruisseau - História de um Riacho, publicado uma década depois.

O início dos anos 1860 é um marco em sua vida pessoal e profissional, marcado pelo nascimento de sua primeira filha, Magali Reclus, bem como pela publicação do Guide de Voyageur à Londres et aux Environs - Guia de Viagem a Londres e Arredores, seu primeiro livro. Além disso, Reclus passa ser convidado a publicar artigos política e anarquismo nas mais importantes revistas europeias, como a Revue Deux Mondes onde publicou 33 artigos, sendo 20 deles sobre o continente americano (SKODA, 2016b), e a Revue Politique et Littéraire, na qual a temática majoritária dos seus textos era a abolição da escravidão.

\footnotetext{
${ }^{8}$ Instituição na qual foi reconhecido como geógrafo e que passou a integrar oficialmente a partir de 1962.
} 
Tanto na academia quanto nos movimentos anarquistas europeus o impacto dos textos de Reclus era cada vez maior" a ponto de ser considerado "uma espécie de embaixador informal dos abolicionistas norte-americanos na Europa" (FERRETTI, 2016). Tal reconhecimento o fez colocar em prática a redação do primeiro volume da obra La Terre: description dus phénomènes de la vie du globe - A Terra: descrição dos fenômenos da vida do globo, composta por dois volumes, considerada sua primeira grande obra de Geografia ${ }^{10}$.

A partir da excelente recepção dos seus escritos analíticos sobre os Estados Unidos e Nova Granada (Colômbia) pelo público francês, a partir de 1862, Reclus dedica-se à compreensão da dinâmica colonial a partir do estudo do caso brasileiro, país que até então não havia visitado, mas que chamara sua atenção em virtude da atração de imigrantes europeus e da manutenção do trabalho escravo. Em dois textos ${ }^{11}$ publicados nas edições de junho e julho de 1862 da conceituada revista Deux Mondes, Reclus descreve o território brasileiro destacando a riqueza hídrica, as populações indígenas da região norte e aos limites territoriais. Entretanto, tece severas críticas em relação ao modelo de organização social do então império porque compreendeu que o poder no Brasil é historicamente concentrado nas mãos de uma aristocracia ligada à manutenção da escravidão e ao monopólio da posse da terra. (RECLUS, 1862a)

É importante lembrar que o discurso de Reclus contra a escravidão era ecoado com sustentação internacional ${ }^{12}$. Mas, além disso, como anticolonialista avesso às imposições do poder constituído, afirmou que tanto sob o domínio português quanto como império (que na prática ainda mantinha o Brasil sob português), a aristocracia brasileira usava os recursos públicos em benefício próprio não se importando com o atendimento das necessidades básicas da população mais pobre. Afirma ainda que, nos centros mais desenvolvidos, ao invés de investir em saneamento, a aristocracia construía palácios suntuosos e praticava ações higienistas em suas ações, fato que promovia a segregação espacial dos mais pobres. (RECLUS, 1862b). Os apontamentos de geógrafo francês sobre o Brasil provocaram a elaboração do primeiro texto brasileiro conhecido analisando um escrito de Reclus, publicado em duas partes ${ }^{13}$ no jornal Diário de Pernambuco ${ }^{14}$ como editorial das edições 223 e 224 de setembro de 1862, contesta os argumentos e critica a análise de Reclus

\footnotetext{
${ }^{9} \mathrm{O}$ reconhecimento da importância destes textos foi tão expressivo que, anos mais tarde, eles foram reunidos e publicados em um livro chamado Viagem à Serra Nevada de Santa-Marta: paisagens da natureza tropical.

${ }^{10}$ As três grandes obras de Élisée Reclus sobre Geografia são: A Terra, Nova Geografia Universal e O Homem e a Terra. É importante salientar que as duas primeiras foram escritas mediante contrato editorial que proibia análises de políticas, econômicas e sociais baseadas aos princípios anarquistas.

${ }^{11} \mathrm{O}$ texto Le Brésil et la Colonisation foi dividido em duas partes: a primeira delas, com 30 páginas, chamada de Le bassin des amazones et les indiens e a segunda, com 40 páginas, intitulada Les provinces du littoral, les noirs et les colonies allemandes. Ver Reclus (1862a e 1862b).

12 Pressões, sobretudo dos ingleses, pelo fim da escravidão.

${ }^{13}$ Originalmente, a intenção era que fosse em 3 partes, mas a última não chegou a ser publicada. Na realidade não se sabe se chegou a ser escrita de fato ou, se foi escrita, qual o motivo da não publicação.

14 DIÁRIO DE PERNAMBUCO. O Brasil e a Colonização. Terra Brasilis. no 7, 2016. Disponível em: $<$ http://journals.openedition.org/terrabrasilis/1931>. Acesso em: 23 jan. 2020.
} 
sobre o Brasil. De acordo com o texto, o que o francês escreveu sobre a oligarquia brasileira precisava ter uma resposta:

[Se ele] escreve e pensa a respeito do nosso país e das nossas coisas na parte mais civilizada do velho mundo; e se por ventura nos é lícito desprezar as invenções ridículas e os aleives grosseiros que enchem os livros e os escritos de charlatães improvisados em viajantes observadores da nossa terra, indispensável se torna refutar os erros que se podem passar como verdadeiros apadrinhados pelo prestígio ou de um nome de autor conhecido, ou de uma publicação periódica justamente apreciada. (DIÁRIO DE PERNAMBUCO, 2016, p. $3)$.

Ainda segundo a crítica, Reclus teria utilizado como fonte de pesquisa trabalhos de autores classificados pelo editorial como ingratos, maledicentes e charlatões:

As fontes principais, as decididamente preferidas pelo Sr. Élisée Reclus, as fontes ele bebeu quase todas as informações que serviram de base ao seu trabalho, foram, o Sr. Élisée Reclus declara, as obras do Sr. Avé Lallemant e do Sr. Biard, os Reise durch Sud-Brazilien im Jahre 1858; Reise durch Nord-Brazilien im Jahre 1859 do primeiro e Deux années au Brésil pelo segundo, isto é, a obra da maledicência e a da ingratidão, ou a do aleive e do charlatanismo.

Para o Sr. Élisée Reclus, o Sr. Avé Lallemant é um viajante que pertence a essa plêiade de sábios que tem elevado as viagens á altura de uma missão social; e o livro do Sr. Biard está cheio de observações engenhosas e de desenhos que são obras primas de verdade.

Fazendo tal juízo dos escritos dos dois viajantes, era impossível que o Sr. Élisée Reclus deixasse de tornar-se muitas vezes eco dos aleives e das falsidades de um, e das extravagantes, imaginarias e ridículas observações do outro. (DIÁRIO DE PERNAMBUCO, 2016, p. 4)

Ao finalizar a crítica, o editorial afirma que as obras de referência utilizadas por Reclus, classificadas por ele como maravilhosas, eram, na verdade, caricaturas da realidade brasileira elaboradas por desconhecedores do território (DIÁRIO DE PERNAMBUCO, 2016). No entanto, mesmo defendendo que os textos de Reclus continham erros históricos e geográficos sobre o Brasil, a crítica do jornal não consegue construir um argumento capaz de invalidar as conclusões do geógrafo francês. Além disso, percebe-se o viés político do editorial conforme já havia apontado o geógrafo Adriano Skoda:

A referência ao artigo de Reclus sobre o Brasil em um jornal do império contudo não era um fato isolado e acidental. A Revue des Deux Mondes, publicada na França, era uma revista de ampla circulação e que tinha como leitores políticos e intelectuais brasileiros. O acesso a Revue des Deux Mondes se estendia também para além dos gabinetes oficiais, cópias da revista estavam disponíveis para o público em geral em espaços como o Gabinete Português de Leitura e no Gabinete Literário, ambos em Pernambuco, a Biblioteca Pública da Bahia, a Biblioteca Fluminense e o Gabinete Português de Leitura do Rio de Janeiro. Por isso, não surpreende que a matéria $O$ Brasil e a colonização, tenha sido publicada no Diário de Pernambuco em Recife poucos meses após sua publicação na revista francesa, uma vez que a capital da província contava com ao menos dois espaços literários em que se encontravam disponíveis a Revue des Deux Mondes. Além disso, o jornal Diário de Pernambuco, de propriedade de Manoel Figueiroa de Faria, era uma espécie de órgão oficial do governo provinciano, trazia em suas páginas análises políticas, econômicas e 
anúncios de toda a província de Pernambuco bem como as principais notícias do império e do exterior. (SKODA, 2016b, p. 3).

Reclus não tomou conhecimento da crítica a seu respeito, mas, mesmo que tivesse ciência dela, por seu perfil intelectual, libertário e contestador não mudaria sua maneira de interpretar o caso brasileiro por causa deste tipo de crítica ${ }^{15}$.

Em 1863, ano do nascimento da sua segunda filha (Jeannie Reclus), Élisée, seu irmão Élie e Jacques Beluze fundam a Crédit au Travail - Crédito no Trabalho, uma espécie de cooperativa cuja intenção era torná-la um "polo de atração dos dissidentes e dos revolucionários sob o Segundo Império" (FERRETTI, 2016, p. 3). Neste mesmo ano, Reclus começa a participar ativamente das organizações que contestavam a ordem imperial francesa. Foi em uma destas articulações que conheceu Mikhail Bakunin, filósofo anarquista russo, de quem foi amigo até a sua morte (ANDRADE, 1985; BRUN, 2014).

Mesmo participando intensamente dos movimentos políticos em Paris, Reclus nunca abandonou a pesquisa e o rigor científico. Entre 1864 e 1868 publica uma série de artigos sobre a Guerra do Paraguai nos quais posiciona-se favorável aos movimentos republicanos da América Latina. No entanto, opõe-se de maneira veemente às políticas do império brasileiro, classificado por ele como autoritário e escravista. Além disso, expõe sua contrariedade à associação do Brasil com Uruguai e Argentina contra o Paraguai: a Tríplice Aliança (RECLUS, 1866 e 1867).

Entre 1868 e 1869, após a publicação dos dois volumes da obra A Terra, Reclus alcançou reconhecimento internacional como um dos maiores especialistas do mundo. A obra foi traduzida para vários idiomas, a versão francesa teve mais de dez reedições. Esse prestígio foi aproveitado por ele para ampliar sua ação política. De acordo com Ferretti (2016, p. 4), "no Congresso da Liga da Paz e da Liberdade em Berna, Reclus pronuncia um discurso de inspiração proudhoniana em favor da ideia federalista, que se baseia também sobre seus trabalhos geográficos”. No entanto, sua visibilidade e seus discursos diretos e incisivos também lhe causaram problemas.

Os anos de 1869 e 1870 foram bastante conturbados para Reclus, tanto em sua prática profissional e militante quanto em sua vida pessoal. Sua ação política foi a causa do seu afastamento da Revue des Deux Mondes, que o considerou demasiado progressista ao defender, por exemplo, a emancipação feminina (VINCENT, 2010; FERRETTI, 2014 e 2016; CIRQUEIRA, 2016). Além disso, outros dois fatos marcaram este período como os mais difíceis de sua vida até então: a morte de sua esposa Clarisse e o afastamento do amigo Bakunin, que passou a considerar

\footnotetext{
${ }^{15}$ A opinião de Reclus sobre o Brasil só irá mudar décadas depois, após o Brasil abolir a escravidão e proclamar a república.
} 
Élie e Élisée Reclus como moderados para o que se esperava de um revolucionário anarquista do século XIX ${ }^{16}$ (VINCENT, 2010, FERRETTI, 2014 e 2016).

No final de 1869, isolado em Paris, Reclus escreve e publica a obra Histoire d'un Ruisseau - História de um Riacho, considerada por muitos estudiosos de sua obra um trabalho de geografia associado à poética. É sua obra acadêmica mais carregada de sentimento e saudosismo.

No ano seguinte, 1870, Reclus decide entrar oficialmente no mundo político francês, candidatando-se à Assembleia Nacional, defendendo como principal pauta de campanha a derrubada do Império e a restauração da república na França, mas não foi eleito. (ANDRADE, 1985; ZAAR, 2015).

Em maio do mesmo ano, Reclus se une à sua segunda esposa, Fynny L’Herminez, sem qualquer cerimônia de cunho religioso, mas com a presença de suas duas filhas que, com a morte da mãe estavam vivendo no interior da França. No entanto, sua felicidade durou pouco mais de um mês porque em julho do mesmo ano, em virtude da eclosão da guerra franco-prussiana, Reclus, aos 40 anos, alista-se como soldado para lutar pela França (GIBLIN, 1971, BRUN, 2014).

A derrota francesa era evidente e ao ser concretizada criou um novo contexto político no território francês, conforme abordado por Andrade (1985, p. 13):

A derrota francesa foi fragorosa. O imperador Napoleão III, que procurava imitar as campanhas de seu tio Napoleão I, já tendo participado de guerras na Itália - pela unificação italiana - e na Rússia - campanha da Criméia - e intervindo no México com a imposição de um imperador - Maximiliano -, pouco resistiu ao exército alemão e foi derrotado em Sedan. Formou-se um governo capitulacionista em Versalhes, que se prontificou a atender todas as exigências dos vencedores, colocando a França em posição humilhante. A população parisiense levantou-se em armas, organizou a Comuna e enfrentou não só os alemães, que realizavam a sua unificação, como também as próprias forças reacionárias o novo governo republicano francês. Reclus, libertário, anarquista, com seus irmãos Paul e Élie, aderiu à Comuna e foi aprisionado, de armas na mão, pelas forças legais.

Reclus foi preso em abril de 1871, após participar ativamente da Comuna de Paris, mas desde julho de 1870 estava afastado de sua esposa e das filhas que, com o conflito intenso em Paris, se refugiaram na terra natal da família Reclus: Sainte-Foy-la-Grande.

Em fevereiro de 1872, após o governo francês receber um documento contendo 61 assinaturas dos mais renomados intelectuais da Europa, Reclus é libertado do cárcere, mas ainda deveria cumprir um período de 10 anos exilado na Suíça. De Paris, foi enviado à Genebra (Suíça) onde reencontrou seu irmão Élie e se reaproximou do antigo Mikhail Bakunin (VINCENT, 2010).

\footnotetext{
${ }^{16}$ A amizade com Bakunin é retomada anos mais tarde, quando Élisée Reclus estava exilado na Suíça.
} 


\section{O SEGUNDO EXÍLIO (1872 a 1885)}

Em território suíço, Reclus fixou moradia na área rural de Lugano, um pequeno município próximo à fronteira com a Itália, onde residiu por dois anos com sua esposa e as duas filhas. Neste período iniciou a redação dos primeiros volumes de sua obra mais extensa: Nouvelle Géographie Universelle - Nova Geografia Universal. (BRUN, 2014; FERRETTI, 2014 e 2016). A retomada da carreira como geógrafo/escritor ocorreu no final de 1872 quando, em uma visita ao irmão Élie, em Zurique, Reclus resolve enviar para Paris o plano de redação da obra, endereçado ao editor da Hachette. (FERRETTI, 2016)

Nos primeiros anos de exílio em território suíço, o geógrafo anarquista, com o objetivo de levantar informações para a redação dos outros volumes de sua grande obra, decide viajar a diversos lugares do mundo. Em 1873, por exemplo, foi à Áustria, conhecer a Exposição Internacional de Viena, na companhia de Attila de Gerando, geógrafo com cidadanias húngara e francesa, considerado o primeiro discípulo de Reclus (VINCENT, 2010; FERRETTI, 2016).

Em 1874, após a morte de sua segunda, Reclus deixa Lugano e passa a residir com as duas filhas nas proximidades de Zurique, região oeste da Suíça, onde, no ano seguinte conhece e se casa com sua terceira esposa, Ermance Gonini. Neste mesmo ano, Reclus recebe a notícia de que o primeiro volume da Nova Geografia Universal havia sido aprovado para publicação, porém em forma de textos semanais ${ }^{17}$. Entretanto a editora se comprometeu a publicar os outros 18 volumes da obra em outros países além da França, a saber: Inglaterra, Espanha e Alemanha (SARRAZAN, 2011).

Mesmo com uma vida mais estabilizada economicamente na Suíça devido ao sucesso como escritor, faltava ainda a retomada das atividades junto à militância anarquista bastante prejudicada desde o seu afastamento forçado do território francês. Essa volta à ação política ocorre a partir de 1877 em Zurique, quando Reclus passa a participar ativamente das atividades da Fédération Jurassienne ${ }^{18}$, a primeira organização anarquista da Suíça, criada por James Guillaume e Mikhail Bakunin, em 1872, após terem sido expulsos da Primeira Internacional dos Trabalhadores, ocorrida durante o congresso em Haia (Holanda). De acordo com Ferretti (2016), esta federação foi a primeira do mundo a adotar o comunismo anarquista como pauta principal e forma de organização.

Além de participar das atividades de organização, Reclus foi um dos integrantes mais ativos da equipe editorial do jornal Le Travailluer de Genebra (VINCENT, 2010; FERRETTI,

\footnotetext{
${ }^{17}$ Segundo Ferretti (2016, p. 4), foi apenas em 1876 que “o primeiro volume completo da Nova Geografia Universal, dedicado à Europa Meridional, [foi] publicado em Paris e [teve] grande sucesso comercial: as primeiras tiragens são ao redor das 20.000 cópias, o que significa um verdadeiro best-seller para aquela época".

18 O nome "Jurassienne" faz referência ao Maciço do Jura, ou Cordilheira do Jura, que também inspirou o termo "Jurássico" para o conhecido período geológico do nosso planeta.
} 
2016), onde publicou vários artigos sobre o anarquismo e inclusive o famoso panfleto Ouvrier, prends la machine! Prends la terre, paysan! - Operário, tome a máquina! Tome a terra, camponês! no qual explica didaticamente a importância do fim da propriedade privada e dos meios de produção. (RECLUS, 1880)

Entre 1879 e 1880, todos os exilados pela participado da Comuna de Paris foram anistiados pelo governo francês e são oficialmente autorizados a retornar. A maioria retorna, mas Reclus opta por permanecer com a família na Suíça (ANDRADE, 1985) porque estava finalizando a redação da obra Histoire d'une Montagne - História de uma Montanha. Além disso, o movimento anarquista suíço estava em ascensão, realizando muitas ações políticas e publicando diversos materiais relacionados ao anarquismo, muitos deles de autoria de Reclus. Neste mesmo momento, na França, o movimento anarquista havia enfraquecido por causa das prisões e mortes de vários integrantes.

Mas, assim como havia ocorrido anos antes no território francês, o crescimento do movimento anarquista na Suíça gerou uma série de reações dos poderes locais, como as ameaças de prisão e o impedimento da divulgação de material relacionado ao pensamento anarquista. A partir de 1881, medidas mais contendentes começaram a ser tomadas, como a expulsão do geógrafo anarquista russo Piotr Kropotkin, que há anos residia em território suíço e era o principal parceiro de militância e referência intelectual de Reclus.

As investidas contra os militantes do movimento anarquista na Europa acabaram promovendo o efeito contrário do qual se pretendia: ao invés de acabar com ele, criou uma rede internacional entre os militantes do movimento. No caso de Kropotkin, por exemplo, quando foi expulso da Suíça ele retornou a Paris, onde retomou e liderou o movimento anarquista francês antes de ser preso novamente.

Ao ser preso na França alguns anos mais tarde, Kropotkin continuou a trocar cartas com Reclus. O assunto principal era a situação do movimento, discutiam possíveis alternativas para sua expansão. Diante deste contexto, o perfil contestador e de enfrentamento de Reclus mais uma vez se faz presente. Kropotkin permaneceu preso até 1886, e, até a sua libertação, Reclus não desistiu de questionar as autoridades francesas sobre quais seriam os argumentos para justificar a prisão do amigo. Mesmo morando na Suíça, Reclus foi várias vezes à França questionar a seletividade da prisão de Kropotkin e em uma carta, enviada no dia 24 de dezembro de 1882 ao juiz de Lyon, onde o amigo estava preso, Reclus questiona:

Senhor,

Li na República de Lyon, em 23 de dezembro, que "de acordo com as instruções", os dois líderes e organizadores dos "anarquistas internacionais" são Élisée Reclus e o Piotr Kropotkin, e que, se eu não compartilho a prisão com meu amigo, é porque "a justiça francesa não pode me agarrar além das fronteiras".

O senhor sabe, no entanto, que teria sido muito fácil me prender, já que passei mais de dois meses na França. O senhor também deve estar ciente de que fui ao funeral de 
Ananieff, em Thonon, no dia seguinte à prisão de Kropotkin e que disse algumas palavras sobre o seu túmulo. Os agentes que estavam imediatamente atrás de mim, e que repetiram meu nome, teriam apenas que me convidar para segui-los.

Mas, se eu moro na França ou na Suíça, isso não importa. Se você deseja ouvir meu julgamento, eu me apressarei em responder ao seu convite pessoal. Diga-me o lugar, dia e hora. Quando chegar a hora, vou bater à porta da prisão designada.

Aceite, senhor, minhas civilidades.

Élisée Reclus ${ }^{19}$

Ao que tudo indica Reclus não obteve resposta. No entanto, uma possível razão para o seu não encarceramento seria o seu prestígio internacional enquanto pensador e intelectual - muito maior o reconhecimento possuía quando foi preso na França pela primeira vez.

Reclus procurou expandir ainda mais a rede internacional dos geógrafos anarquistas. Em virtude desse trabalho, volta várias vezes à França, inclusive chegando a passar meses no país, como em 1882 quando além das atividades como militante anarquista participou das cerimônias de casamento das filhas: Magali Reclus, com o engenheiro e arquiteto Paul Régnier, e Jeannie Reclus, com o engenheiro químico Léon Cuisinier (VINCENT, 2010). Essa cerimônia é um fato marcante na biografia de Reclus porque, como o pai das noivas, proferiu um discurso no qual pregava a união livre entre as pessoas, o que provocou grande indignação entre os religiosos conservadores e teve enorme repercussão na imprensa local (FERRETTI, 2016). Este episódio também é particularmente importante porque Reclus havia assinado um contrato com a editora dos seus livros no qual se comprometia a não abordar temas como religião, costumes e política em seus escritos publicados por ela (GIBLIN, 1982; ANDRADE, 1985). Com a repercussão negativa do discurso, foi cogitada a possibilidade de interromper a publicação de suas obras. No entanto, a medida foi descartada tendo em vista a grande aceitação das obras pelo mercado editorial.

Após a repercussão do discurso proferido no casamento das filhas, Reclus retorna à Suíça e começa a planejar uma série de viagens para coleta de dados para a redação de mais quatro volumes da Nova Geografia Universal. Entre 1883 e 1885 realiza estas viagens visitando a Grécia, o oeste da

\footnotetext{
${ }^{19}$ No original, em francês:

Monsieur,

Je lis dans le Lyon Républicain du 23 décembre que «d'après l'instruction», les deux chefs et organisateurs des «anarchistes internationaux» sont Élisée Reclus et le Piotr Kropotkin, et que, si je ne partage pas la prison de mon ami, c'est que «la justice française ne peut aller me saisir au-delà des frontières».

Vous savez pourtant qu'il eût été bien facile de m'arrêter, puisque je viens de passer plus de deux mois en France. Vous n'ignorez pas non plus que je me suis rendu à Thonon pour l'enterrement d'Ananieff, le lendemain de l'arrestation de Kropotkin, et que j'ai prononcé quelques paroles sur la tombe. Les agents qui se trouvaient immédiatement derrière moi et qui se répétaient mon nom, n'avaient qu'à m'inviter à les suivre.

Mais, que je réside en France ou en Suisse, il importe peu. Si vous désirez instruire mon procès, je m'empresserai de répondre à votre invitation personnelle. Indiquez-moi le lieu, l'heure, le jour et l'heure. Au moment fixé, je frapperai à la porte de la prison désignée.
} 
Ásia e ao norte da África (FERRETTI, 2016). Esta última região despertou profundo um interesse no geógrafo anarquista porque comprovava seus argumentos contrários ao colonialismo europeu ${ }^{20}$.

\section{MILITÂNCIA, PRESTÍGIO E DOCÊNCIA (1886 - 1895)}

Com várias obras conhecidas em toda Europa, o pensamento de Reclus alcança uma aceitação ainda maior tanto entre militantes de movimentos sociais quanto entre os acadêmicos, inclusive em países nos quais o mercado editorial francês tinha dificuldade de aceitação, como Inglaterra, Noruega e Suécia. Tal fato se deve - além da importância das suas obras para a compressão do mundo no final do século XIX - pela atuação de Kropotkin que, após cumprir sua pena de três anos na França, passa a viver em Londres. Em reuniões e ações políticas com geógrafos ingleses ressaltava a relevância das obras de Reclus que evidenciavam as diferenças entre as formas de desenvolvimento existentes nas regiões do mundo e comprovavam o caráter nocivo do colonialismo europeu para a liberdade das pessoas. Assim, Reclus passa a ser uma das maiores referências da geografia europeia. Sua Geografia Social - baseada na luta de classes, na busca pelo equilíbrio e na decisão soberana do indivíduo, categorias movimentadas no bojo da relação dialética evolução-revolução (RECLUS, 1905 e 2002) - torna-se referência metodológica para estudos de vários geógrafos ingleses ${ }^{21}$.

Em 1888 Reclus resolve deixar a Suíça. Dois fatos foram fundamentais para essa decisão: a morte do genro Léon Cuisinier, seu parceiro de viagens, e a morte do biólogo russo Léon Metchnikoff, seu principal consultor/colaborador científico. Mas, antes de deixar definitivamente a Suíça, Reclus realiza sua segunda viagem à América do Norte para coletar informações para a finalização dos volumes 16 e 17 da Nova Geografia Universal (FERRETTI, 2016). Ao retornar da América do Norte, já em 1890, em uma tentativa de manter o renomado intelectual em território suíço, um grupo de intelectuais o convida para assumir a cátedra de Geografia na Universidade de Genebra. O convite foi recusado porque Reclus estava comprometido com a finalização dos últimos volumes de sua maior obra.

Em 1892, residindo nos arredores de Paris, Reclus será finalmente reconhecido pela Sociedade de Geografia de Paris. A condecoração ocorreu em virtude da contribuição fornecida

\footnotetext{
${ }^{20}$ Não se sabe exatamente quantas vezes Reclus foi à região norte do continente africano, mas passou por vários lugares. A Argélia, onde uma de suas filhas chegou a residir por causa do trabalho do marido engenheiro, foi o país que mais lhe chamou atenção. Isso pode ser notado tanto em seus escritos sobre anticolonialismo, quanto pela leitura de correspondências que ele escrevia.

${ }^{21}$ A divulgação das obras de Reclus contou também com o apoio de renomados pesquisadores anglo-saxões, entre eles: o biólogo e filósofo escocês Patrick Geddes, o jornalista e etnógrafo irlandês Augustus Henry Keane, o geógrafo e meteorologista escocês Hugh Robert Mill, o geógrafo inglês Halford John Mackinder, e o geógrafo escocês John Scott Keltie. (VINCENT, 2010; FERRETTE, 2011, 2014 e 2016; ZAAR, 2015)
} 
pelos volumes até então publicados da Nova Geografia Universal ${ }^{22}$. Contudo, para completar o ciclo de grandes viagens pelo mundo e finalizar a coleta de dados para os dois últimos volumes desta obra (tomos 18 e 19), embarca para a América do Sul, em junho de 1893, para aquela que seria sua última grande expedição, que durou aproximadamente seis meses, na qual passou por Brasil, Argentina, Uruguai, Chile e guianas.

Especialmente no Brasil, a chegada de Reclus contou com todas as honrarias e cerimoniais dignos dos maiores intelectuais do mundo ${ }^{23}$. Foi homenageado pelo Instituto Histórico e Geográfico Brasileiro $^{24}$ (em 30 de junho) e pela Sociedade de Geografia do Rio de Janeiro ${ }^{25}$ (em 18 de julho) ${ }^{26}$.

O interesse do geógrafo francês em terras brasileiras era compreender o contexto social e político do período iniciado poucos anos antes (com a abolição da escravidão, em 1888, e a proclamação da república, em 1889), pois alteraram sua visão sobre o país. Além disso, seu encantamento com o meio natural brasileiro também ficou evidente na obra Estados Unidos do Brasil: geografia, etnografia, estatística ${ }^{27}$. Reclus acreditava que, por ser um país miscigenado, o Brasil poderia ser futuramente um exemplo para a luta contra o racismo.

Em 1894, de volta à Europa e trabalhando na redação dos dois últimos volumes da Nova Geografia Universal, Reclus foi convidado para ser docente da Université Libre de Bruxelles (Bélgica). O convite foi aceito, mas logo após sua mudança para a capital belga, sua nomeação foi revogada em virtude da ação de pessoas da instituição comprometidas com o combate às ideias anarquistas. Segundo Ferretti (2016, p. 6), “a revogação de sua contratação, decidida no clima de paranoia anti-anarquista que seguiu os atentados dos ditos individualistas franceses, provoca o incidente Reclus", que culminou na cisão dos professores da Universidade Livre de Bruxelas em dois grupos. Aqueles que defendiam a permanência do anarquista francês no quadro de docentes estiveram entre os responsáveis pela criação da Université Nouvelle de Bruxelles, fundada em outubro de 1894, na qual Reclus ministrou a disciplina Geografia Comparada no Espaço e no Tempo.

\footnotetext{
${ }^{22}$ A monumental obra Nouvelle Géographie Universelle, composta por dezenove volumes, só foi finalizada em 1894 , com a publicação do segundo volume sobre a América do Sul, intitulado Amérique du Sud: l'amazonie et la plata, no qual Reclus disserta sobre Guiana, Brasil, Paraguai, Uruguai e Argentina.

${ }^{23}$ De acordo com Azevedo (2002), Lopes (2004 e 2009) e Miyahiro (2011), muitos anos antes da chegada de Reclus ao Brasil, suas obras, originais em língua francesa, já eram lidas e discutidas por vários escritores/intelectuais brasileiros.

${ }^{24}$ Instituto Histórico e Geográfico Brasileiro. Ata da $8^{a}$ Sessão Ordinária, de 30 de junho de 1893 . Rio de Janeiro. Instituto Histórico e Geográfico Brasileiro, 1893.

${ }^{25}$ Andrade (1985), Lopes (2009) e Miyahiro (2011).

${ }^{26}$ Alguns anos depois, em outubro de 1898, Reclus foi escolhido (juntamente com Eça de Queiros, Conde Leão Tostoi, entre outros ilustres) como um dos membros correspondentes da Academia Brasileira de Letras. A sessão para a sua indicação, presidida por Machado de Assis, também contou com a presença de Graça Aranha, Joaquim Nabuco, Visconde de Taunay etc. (ACADEMIA BRASILEIRA DE LETRAS, 1898).

${ }^{27}$ Texto escrito por Élisée Reclus para compor os últimos volumes de Nouvelle Géographie Universelle, mas traduzido e publicado em português em 1900. Ver Reclus, 1900.
} 
Em 1895 Reclus inicia a redação de sua última grande obra geográfica: O Homem e a Terra, voltada à metodologia da geografia na qual apresenta de forma analítica a Geografia Social. Neste mesmo ano, elabora seu projeto mais controverso, conhecido como Globe au 100.000 Globo na escola de 1:100.000, publicado sob o título de Projet de construction d'un globe terrestre à l'échelle du cent-millième - Projeto de construção de um globo terrestres na escala de cem mil. $\mathrm{O}$ projeto - que deveria ser construído em quatro anos para ser apresentado ao grande público na Exposição Universal que ocorreria entre abril e novembro de $1900 \mathrm{em}$ Paris - previa a construção de um grande edifício em formato de globo terrestre, com aproximadamente 200 metros de altura e 160 metros de diâmetro. De acordo com o projeto, a construção seria composta por três esferas, uma dentro da outra. A maior, a exterior, seria composta por vidro e ligas metálicas. A segunda camada seria a representação da crosta terrestre, e a terceira, a mais interior da construção, abrigaria um espaço para exposições e uma biblioteca (RECLUS, 1895). O objetivo era apresentar ao grande público os aspectos geográficos das diversas regiões do planeta. No entanto, embora tenha despertado interesse do governo francês, o projeto nunca foi realizado em virtude de seu alto custo $^{28}$.

Uma análise mais atenta do projeto revela importantes elementos para discutir a sua visão de geografia no final do século XIX, momento em que a Geografia já estava consolidada como ciência na Europa. Por exemplo: para Reclus, a visão bidimensional do mundo, baseada em cartas e mapas, precisava ser superada, tanto pelos geógrafos quanto pela população em geral (RECLUS, 1895, 1901 e 1903). Assim, a Geografia deveria primar pela superação da visão eurocêntrica, tradicional, que em nada representava os princípios de uma sociedade fraterna e mais justa. (RECLUS, 1895)

\section{OS ÚLTIMOS DEZ ANOS DE VIDA... (1896 - 1905)}

Os últimos anos do século XIX foram marcados pela proximidade do geógrafo francês com os intelectuais do Reino Unido, sobretudo com Patrick Geddes, um dos pioneiros do planejamento urbano. De acordo com Ferretti (2016), os apontamentos realizados anos antes por Reclus e Kropotkin durante a expansão intelectual e política do movimento anarquista na Europa, influenciaram a trajetória de Geddes em relação à elaboração de conceitos como conurbação e planeamento regional. Neste contexto, a pedido de Geddes, Élisée Reclus e seu irmão Élie, escrevem o texto Renouveau d'une Cité - Renovação de uma Cidade (RECLUS; RECLUS, 1896),

\footnotetext{
${ }^{28}$ De acordo com Vincent (2010) e Ferretti (2014 e 2016), em 1898 Reclus chegou a apresentar e defender a viabilidade do seu projeto na Royal Geographical Society em Londres, mas na época, estimou-se que o projeto do globo de Reclus custaria o dobro do que custou a torre Eiffel (o custo da torre foi pago pelo governo estadunidense, em retribuição à estátua da liberdade, presente do governo francês ao povo americano).
} 
no qual abordam aspectos relacionados aos movimentos de renovação urbana e tornou-se referência para os urbanistas europeus.

Nos primeiros anos do século XX, a credibilidade dos escritos de Reclus era tão expressiva que suas obras passaram a ser utilizadas para sustentar argumentos jurídicos em processos e decisões de magistrados em sentenças judiciais, sobretudo em processos envolvendo o litígio de fronteiras. O exemplo mais conhecido desta utilização foi a decisão de uma ação impetrada da Guiana, que reivindicava uma parte do estado do Pará, contra o Brasil. A sentença, favorável ao Brasil, foi tomada a partir de um mapa de Reclus. (FERRETTI, 2013).

Já com a saúde debilitada, entre os anos de 1901 e 1903, Reclus proferiu uma série de conferências de cunho metodológico na Europa, com destaque para: palestra na Gesellschaft für Erdkunde (Sociedade Geográfica de Berlim), fundada por Carl Ritter e Alexander von Humboldt em 1828, considerada a mais importante da Europa; e na Royal Geographical Society (Sociedade Geográfica Real) de Londres. Nestas palestras, defendeu que os geógrafos deveriam se ater aos mapas tridimensionais, sobretudo no ensino da Geografia, pois, segundo ele, o uso dos tradicionais mapas e cartas bidimensionais não é capaz de mostrar a verdadeira face dos lugares, tornando o aprendizado da Geografia desestimulante (RECLUS, 1901 e 1903).

Os anos de 1904 e 1905, Reclus reside em Thorout, uma pequena cidade localizada a 100 km a oeste de Bruxelas, onde, mais recluso, foi informado sobre o início da publicação de obra $O$ Homem e a Terra, organizada por seu sobrinho Paul Reclus (VINCENT, 2010; FERRETTI, 2016).

Em 4 de julho de 1905, Jacques Élisée Reclus falece em casa, ao lado da esposa Florence. Seu sepultamento ocorreu no mesmo túmulo que seu irmão Élie, falecido no ano anterior, no cemitério de Ixelles em Bruxelas, próximo ao campus da universidade.

\section{CONSIDERAÇÕES FINAIS}

O texto aqui apresentado buscou auxiliar leitores e estudiosos do aporte teórico de Reclus a compreender aquilo que este pensador sempre deixou bastante claro em suas obras, em suas cartas ou nos seus discursos: que não há como separar o pensamento, a teoria, da ação social visando a transformação da realidade. Neste sentido, o artigo apresentado também fornece importantes elementos para a compreensão de temas importantes tanto para a Geografia quanto para as demais áreas das Ciências Humanas sob a perspectiva libertária de Reclus, a saber: evolução do pensamento geográfico, teoria e método em Geografia, crises políticas europeias, consolidação do movimento anarquista, a questão do exílio como estratégia autoritária de repressão da intelectualidade e a questão do colonialismo como elemento fundamental da consolidação do modo de produção capitalista. 
Por conseguinte, o intento do texto apresentado, longe de ser uma análise entre agência e estrutura, é ser um recurso didático, um material de apoio, a todos aqueles que pretendem entender melhor o significado da expressão "vida libertária”, muito empregada para adjetivar Élisée Reclus. Além disso, organizado cronologicamente - tanto a partir de informações colhidas no decorrer de nossas pesquisas sobre a obra geográfica do autor em questão, quanto em textos sobre ele (como de Brun, Ferretti, Giblin,Vincent etc.) - buscou-se, de forma didática, fornecer ao leitor subsídios para um posterior aprofundamento nas ideias ácratas do pensador estudado, tendo em vista que vários estudos acadêmicos, ainda que com a nobre intenção em estudar o método de Reclus, acabam incorrendo no erro de separar seu pensamento de sua vida. Tal fato é especialmente grave quando estudamos Reclus porque seu pensamento não foi construído em ambientes acadêmicos, mas na militância, na ação social. Seu método e pensamento foram construídos no bojo das profundas transformações políticas, sociais e econômicas ocorridas no mundo no século XIX, também caracterizado pelo cerceamento, e até repressão, ao movimento ácrata.

\section{REFERÊNCIAS}

ACADEMIA BRASILEIRA DE LETRAS. Ata da Sessão de 25 de outubro de 1898. Rio de Janeiro: ABL, 1898. 44p.

ANDRADE, M. C. (Org.). Élisée Reclus. São Paulo: Ática, 1985. 201p.

AZEVEDO, M. H. C. Um senhor modernista: biografia de Graça Aranha. Rio de Janeiro: Academia Brasileira de Letras, 2002. 509p.

BERDOULAY, V. La Formation de l'école Française de Géographie (1870-1914). Annales de Géographie, v. 90, n. 502, p. 734-737, 1981.

BESSE, J. M. La géographie dans le mouvement des sciences au tournant du siècle. In: BORD, J. P. ; RAFFAELE, C. ; CREAGH, R. ; MIOSSEC, J. M. ; ROQUES, G. (Orgs.) Élisée Reclus e Paul Vidal de La Blache: Le Géographe, la Cité et le Mode hier et aujourd'hui. L'Harmattan: Paris, 2009. p. 271-279.

BOINO, P. O Pensamento Geográfico de Élisée Reclus. In: RECLUS, É. Da ação humana na geografia física: Geografia comparada no espaço e no tempo. São Paulo: Editora Imaginário, 2010. p. 9-39.

BRUN, C. Une vie d'Élisée Reclus en trente dates. RECLUS, É. Les Grands Textes. Paris: Champs Classiques, 2014, p. 415-433.

BRUN, C. Élisée Reclus, une chronologie familiale: sa vie, ses voyages, ses écrits, ses ascendants, ses collatéraux, les descendants, leurs écrits, sa postérité (1796-2015) tableaux généalogiques, documents, cartes. $2015 . \quad$ Daforum, Disponível em: http://raforum.info/reclus/spip.php?article474\&lang=fr. Acesso em: 20 jan. 2020. 
CIRQUEIRA, J. V. Élisée Reclus e a excentricidade de sua geografia anarquista. Terra Brasilis, $\mathrm{n}$. 7, p. 1-18, 2016.

CUBERO, J. Apresentação. RECLUS, É. A evolução, a revolução e o ideal anarquista. São Paulo: Imaginário, 2002. p. 9-18.

DIÁRIO DE PERNAMBUCO. O Brasil e a Colonização. Terra Brasilis. n ${ }^{\circ}$ 7, 2016, p. 1-16. Disponível em: http://journals.openedition.org/terrabrasilis/1931. Acesso em: 23 jan. 2020. Republicado de: DIÁRIO DE PERNAMBUCO, $\mathrm{n}^{\circ} 223$, p. 8 (27 de setembro de 1862) e $\mathrm{n}^{\circ} 224$, p. 8 (29 setembro de 1862).

FERRETTI, F. L'Occident d'Élisée Reclus: l'invention de l'Europe dans la Nouvelle Géographie Universelle (1876-1894). Thèse de Doctorat. Université Panthéon-Sorbonne - Paris I, 2011. Disponível em: https://tel.archives-ouvertes.fr/tel-00986085/document. Acesso em: 24 jan. 2020.

FERRETTI, F. Le fonds Reclus-Perron et le contesté franco-brésilien de 1900. Terra Brasilis, n, 2, p. 1-19, 2013.

FERRETTI, Federico. Élisée Reclus: pour une géographie nouvelle. Paris: Editions du CTHS, 2014.

FERRETTI, F. Breve Cronologia da Vida de Élisée Reclus (1830-1905). Terra Brasilis, n. 7, p. 1$6,2016$.

GIBLIN, Béatrice. Élisée Reclus: géographe. Thèse de Doctorat. Université de Paris VIII, Paris, 1971.

GIBLIN, B. Géographie et anarchie: Élisée Reclus. Hérodote, n. 2, p. 30-49, 1976.

GIBLIN, B. Élisée Reclus, 1830-1905. Hérodote, n. 22, p. 6-13, 1981.

GIBLIN, B. Introduction et choix des textes. In: RECLUS, É. L'Homme et la Terre. Paris: François Maspero, 1982. p. 8-19.

GIBLIN, B. Élisée Reclus: un géographe d'exception. Hérodote, n. 117, p. 11-28, 2005.

LACOSTE, Y. Editorial. Élisée Reclus. Hérodote, n. 22, p. 3-5, 1981.

LOPES, M. Crônica dos primeiros anarquistas no Rio de Janeiro (1888-1900). Rio de Janeiro: Achiamé, 2004. 71p.

LOPES, M. Élisée Reclus e o Brasil. GEOgraphia, Niterói, v. 11, n. 21, p. 160-175, 2009.

MARTINS, J. S. O Cativeiro da Terra. São Paulo: LECH/USP, 1981. 288p.

MIOSSEC, J. M. Introduction. In: BORD, J. P. ; RAFFAELE, C. ; CREAGH, R. ; MIOSSEC, J. M. ; ROQUES, G. (Orgs.) Élisée Reclus e Paul Vidal de La Blache: Le Géographe, la Cité et le Mode hier et aujourd'hui. L'Harmattan: Paris, 2009. p. 7-8. 
MIYAHIRO, M. A. O Brasil de Élisée Reclus: território e sociedade em fins do século XIX. 2011. 146 f. Dissertação (Mestrado em Geografia Humana) - Faculdade de Filosofia, Letras e Ciências Humanas, Universidade de São Paulo, São Paulo, 2011.

PROUDHON, Pierre-Joseph. Qu'est-ce que la propriété? recherche sur le principe du Droit et du Gouvernement. Paris: Lacroix Éditeurs, 1840. 278p.

RECLUS, É. Développement de la Liberté dans le Monde. Journal Le Libertaire, Paris, n $^{\text {o }} 22$ (28 de agosto), $\mathrm{n}^{\mathrm{o}} 23$ (04 de setembro), $\mathrm{n}^{\mathrm{o}} 25$ (18 de setembro), $\mathrm{n}^{\mathrm{o}} 26$ (25 de setembro) e $\mathrm{n}^{\mathrm{o}} 27$ (02 de outubro), 1925.

RECLUS, É. Le Brésil et la Colonisation: le bassin des amazones et les indiens. Revue des Deux Mondes, Paris, p. 931-959, 1862.

RECLUS, É. Le Brésil et la Colonisation: les provinces du littoral, les noirs et les colonies allemandes. Revue des Deux Mondes, Paris, p. 376-414, 1862.

RECLUS, É. Les Républiques de l'Amérique du Sud : leurs guerres et leur projet de fédérations. Revue des Deux Mondes, Paris, p. 908-953, 1866.

RECLUS, É. La Guerre du Paraguay. Revue des Deux Mondes, Paris, p. 934-965, 1867.

RECLUS, É. L'Histoire d'un Ruisseau. Paris: Hetzel, 1869. 195p.

RECLUS, É. Ouvrier, prends la machine! Prends la terre, paysan! Genève: Imprimerie Jurassienne, 1880.

RECLUS, É. Projet de construction d'un globe terrestre à l'échelle du cent-millième. Bruxeles: Société Nouvelle, 1895.

RECLUS, É. Estados Unidos do Brasil: geografia, etnografia, estatística. Rio de Janeiro: Garnier, 1900. 488p.

RECLUS, É. L'enseignement de la géographie: globes, disques globulaires et reliefs. Bruxelles. Nouvelle Université Libre, n. 5, p. 29-38, 1901.

RECLUS, É. L'enseignement de la géographie. Bruxelles. Bulletin de la Société Belge d'Astronomie, n. 11, p. 5-11, 1903.

RECLUS, É. L'Homme et la Terre - tome I. Paris: Librairie Universelle, 1905.

RECLUS, É. A evolução, a revolução e o ideal anarquista. São Paulo: Imaginário, 2002. 136p.

RECLUS, É. Da ação humana na geografia física: Geografia comparada no espaço e no tempo. São Paulo: Editora Imaginário, 2010. 96p.

RECLUS, É. Anarquia pela educação. São Paulo: Hedra, 2011. 104p.

RECLUS, É.; RECLUS, É. Renouveau d'une Cité. Revue Société Nouvelle. Bruxelles: Édition Société Nouvelle, 1896. 
SARRAZIN, H. Introduction. In: RECLUS, É. L’Anarchie. Nouvelle Édition Augmentée. Paris: Éditions du Sextant, 2011.

SILVA, R. R. Élisée Reclus e a Escola Moderna de Francisco Ferrer y Guardia. Terra Brasilis (Nova Série), v. 7, p. 1-13, 2016.

SKODA, A. G. A Recepção de Élisée Reclus no Brasil: uma narrativa científica. 2016. 147 f. Dissertação (Mestrado em Geografia Humana) - Faculdade de Filosofia, Letras e Ciências Humanas. Universidade de São Paulo, São Paulo, 2016a.

SKODA, A. G. Editorial. Terra Brasilis, n. 7, p. 1-17, 2016. 2016b, p. 1-17.

VINCENT, J. D. Élisée Reclus: géographe, anarchiste, écologiste. Éditions Robert Laffont: Paris, 2010. 421p.

ZAAR, M. H. Élisée Reclus e o seu método geográfico. Biblio 3W. Revista Bibliográfica de Geografía y Ciencias Sociales. Barcelona, v. 20, n. 1123, p. 1-35, 2015.

Trabalho enviado em $23 / 03 / 2020$

Trabalho aceito em 08/10/2020 